\title{
Imperforate Hymen Complicated with Genital Mutilation: A Case Report
}

\author{
Mohamed Alkhatim Alsammani*
}

Department of Obstetrics and Gynecology, Qassim University, College of Medicine, Saudi Arabia

\begin{abstract}
There are an estimated 130 million victims of female genital mutilation (FGM) worldwide, mostly in Africa, and two million such procedures are performed every year. FGM is associated with many immediate and long-term complications.

This study examines a case of an imperforated hymen in a premenarcheal adolescent girl presented with acute retention of urine. Eight months prior, she was treated in a rural health center for a case of recurrent urinary tract infection attributed to genital mutilation. She was diagnosed via pelvic ultrasound with hematometria due to an imperforated hymen and treated successfully with decircumcision and a cruciate hymenotomy.
\end{abstract}

Keywords: Circumcision; Hematocolpos; Hematometra; Imperforate; Hymen

\section{Introduction}

An imperforate hymen is an uncommon obstructive anomaly of the female reproductive tract. The hymen is derived from the urogenital sinus. An imperforate hymen results from failure of canalization of the hymeneal membrane during embryonic life, which results in the occlusion of the vaginal orifice. Prior to puberty, this condition is rarely diagnosed, as it is usually asymptomatic. After puberty, this congenital anomaly will cause many symptoms, including primary amenorrhea and cyclical abdominal pain [1].

Female genital mutilation comprises all procedures that involve partial or total removal of the external female genitalia or other injury to the female genital organs for non-medical reasons [2]. It is also known as female genital cutting or female circumcision. FGM is performed at any time from birth to just before marriage but is most commonly performed between the ages of four and ten years [3]. The following report illustrates the difficulty in clinical diagnosis of an imperforated hymen in the presence of genital mutilation and how morbidity from imperforated hymen resulting from such a procedure may be reduced. In addition, it is advantageous to increase awareness among clinicians to conduct genital examination of a newborn girl part of their routine practice.

\section{Case Report}

A 14-year-old girl treated by the emergency gynecological department on October 8, 2011 presented with acute retention of urine lasting for one day. She had been complaining of lower abdominal pain, bilateral loins pain and dysurea for the previous eight months. During this period, she sought treatment from a general practitioner for recurrent urinary tract infections. At the age of four, she underwent genital mutilation (circumcision). She did not present symptoms of associated nausea, vomiting, diarrhea, bowel symptoms or vaginal discharge and had a strong appetite. The patient had no previous history of acute retention of urine. She had not yet experienced menses. Her past medical history did not reveal any significant complications, and she did not have a family history of similar conditions.

On physical examination, she appeared uncomfortable. Her vital signs were as follows: the temperature was $38^{\circ} \mathrm{C}$, the heart rate was 80 beats/minute, the respiratory rate was 18 breaths/minute and her blood pressure was $90 / 60 \mathrm{~mm} \mathrm{Hg}$. She exhibited well-developed secondary sexual characteristics. Her abdomen was soft and not distended. On palpation, medical personnel detected diffuse tenderness in the lower abdomen but no rebound tenderness. There was a mass arising from the pelvis of 12 weeks size. Perineal examination showed type IV genital mutilation (narrowing of the vaginal orifice with creation of a covering seal by cutting and positioning of both labia minora and the labia majora, with excision of the clitoris) [4]. Rectal examination showed good sphincter tone with a large mass felt anteriorly. The remainder of the physical examination was unremarkable.

The laboratory findings indicated a $\mathrm{Hb}$ of $9.5 \mathrm{~g} / \mathrm{dl}$ and a white blood cell count of 13,000 and blood type was $\mathrm{O}$ positive. The urine analysis revealed that the number of white blood cells was too large to count. No organisms were isolated from the urine culture. A urine pregnancy test was negative. Trans-abdominal sonography showed a hyperechogenic mass filling the whole uterine cavity (old blood) consistent with hematometria due to imperforated hymen (Figure 1). A renal scan showed dilated pelvicalyceal system suggestive of lower obstruction with mild hydronephrosis (Figure 2). The bladder was distended with an altered contour.

One the same day, decircumcision and a cruciate hymenotomy were performed under general anesthesia; approximately $500 \mathrm{ml}$ of chocolate-colored fluid was drained. The patient's postoperative recovery was uneventful. She was discharged on the second day and she was scheduled for follow-up.

\section{Discussion}

An imperforate hymen is an uncommon obstructive anomaly of the female reproductive tract. Estimates of its frequency vary from one case per 1000 persons to one case per 10,000 persons. However, the exact prevalence remains uncertain [5]. Although the condition is usually sporadic, but it tends to occur in families [6]. In the pre-pubescent stage, diagnosis is extremely difficult since the condition is asymptomatic and does not affect quality of life. In adolescent girls, it should be suspected in those present with amenorrhea, lower abdominal pain and acute retention of urine. In most of the relevant literature, diagnosis of an imperforate hymen was established when blood collection in the

*Corresponding author: Mohamed Al-khatim Alsammani, Department of Obstetrics and Gynecology, Qassim University, College of Medicine, Saud Arabia, Tel: +966568525808; E-mail: m_sammani@yahoo.com

Received November 17, 2011; Accepted January 05, 2012; Published January 13,2012

Citation: Alsammani MAM (2012) Imperforate Hymen Complicated with Genital Mutilation: A Case Report. J Clinic Case Reports 2:107. doi:10.4172/2165-7920.1000107

Copyright: (C) 2012 Alsammani MAM. This is an open-access article distributed under the terms of the Creative Commons Attribution License, which permits unrestricted use, distribution, and reproduction in any medium, provided the original author and source are credited. 
Citation: Alsammani MAM (2012) Imperforate Hymen Complicated with Genital Mutilation: A Case Report. J Clinic Case Reports 2:107. doi:10.4172/2165-7920.1000107

Page 2 of 2

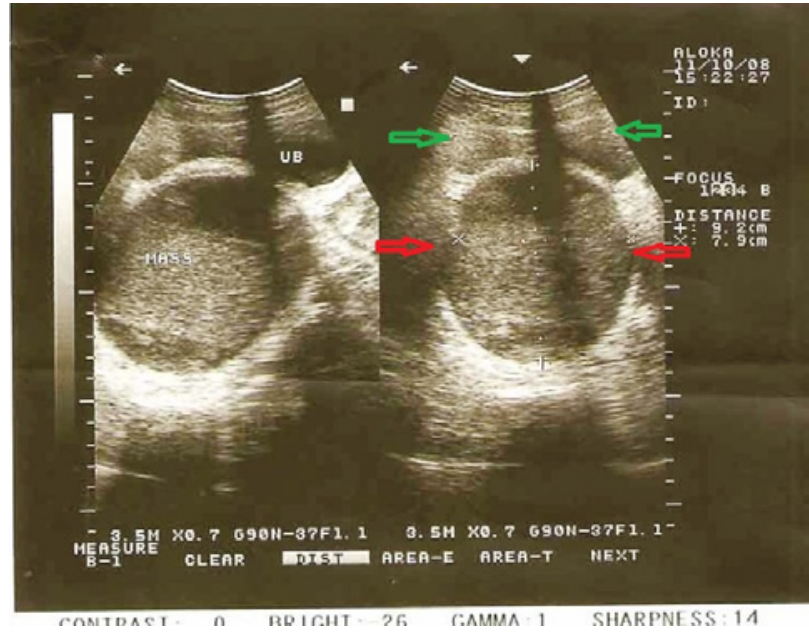

Figure 1: The sonographic image of the urinary bladder (green arrow). The uterine cavity (red arrow) filled by a mass (old blood) Size $(9.8 \times 7.9 \mathrm{~cm})$ in a 14-year-old girl with an imperforate.

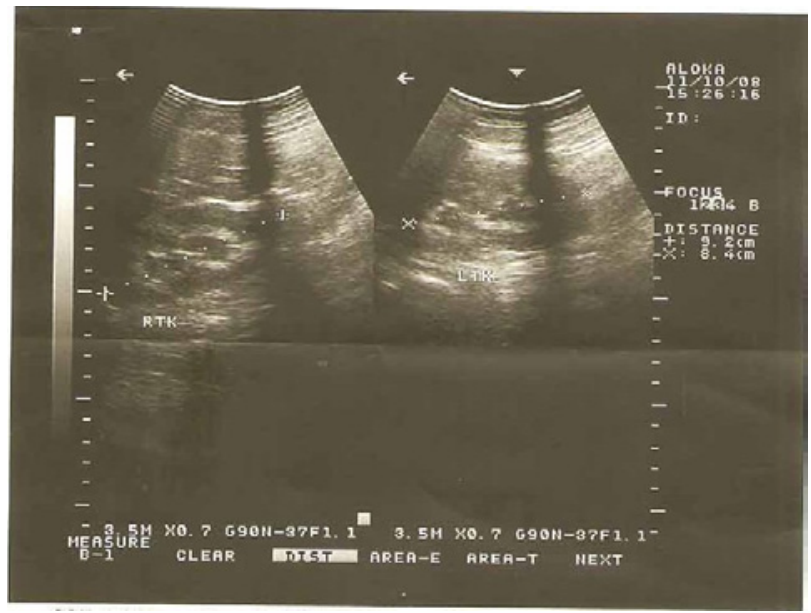

Figure 2: Ultrasound of both kidneys of the same patient. Note the dilatation of the plevicalcyeal system with evidence of mild hydronephrosis with urinary stasis due to distal obstruction.

vagina and the uterus formed an expanding pelvic mass, inducing symptoms as result of the mechanical effect on the urethra [6,7]. In other words, the condition is usually diagnosed late. Early diagnosis of an imperforate hymen in adolescent girls with primary amenorrhea could have a positive impact on timely gynecological treatment with a reduction of morbidity associated with this disorder. In the present study, the patient had recurrent urinary infection for eight months before having acute retention of urine. Such symptoms may indicate early collection of blood in the vagina leading to partial occlusion of the urethra and causing recurrent urinary tract infection.

An imperforated hymen is an easily diagnosable congenital anomaly. Almost in all studied cases the demonstration of a bluish membrane bulging through the vaginal orifices after labial retraction is an invariable finding. In countries where genital mutilation is practiced, perineal examination is not informative, especially in patients with type III (Narrowing of the vaginal orifice with creation of a covering seal by cutting and appositioning the labia minora and/or the labia majora, with or without excision of the clitoris) [4] and IV genital mutilation, as seen in the above case. This is always established by pelvic ultrasound and the demonstration of old blood in the vagina and the uterus. FGM does not only preclude the diagnosis of an imperforated hymen but can lead to serious urinary tract infection and calculus formations $[8,9]$. These can double the risk of infection in the kidneys posed already by an imperforated hymen. Follow-up and screening for urinary tract infections is essential to preventing chronic renal infection, as seen in our case. In countries where FGM is practiced, it will be a good practice if the external genitalia of any newborn girl is examined for an imperforated hymen. Furthermore, any premenarcheal adolescence girl that presents with urinary symptoms and lower abdominal pain should undergo pelvic ultrasound to rule out an imperforated hymen.

\section{Conclusion}

FGM has the possibility of severe immediate and long-term implications. In addition to obscuring diagnosis of imperforate hymen, FGM may result in recurrent obstruction and, potentially, in ascending renal infection as seen in the above case. Concerted efforts by health providers and health authorities in communities where FGM is common must have additional laws to reduce this repugnant and unacceptable malpractice against human rights.

\section{Acknowledgment}

We thank Faiza Mirghani Mousa, the sonographer, for her assistance with providing photos.

\section{References}

1. Radhakrishnan J, Reyes HM (1982) Unilateral renal agenesis with hematometrocolpos: Report of two cases. J Pediatr Surg 17: 749-750.

2. World Health Organization (1997) Female genital mutilation. Geneva: World Health Organization.

3. Fox EF, de Ruiter A, Bingham S (1997) Female genital mutilation. Int J STD AIDS 8:599-601.

4. World Health Organization (2008) Eliminating Female Genital Mutilation-An interagency statement OHCHR, UNAIDS, UNDP, UNECA, UNESCO, UNFPA, UNHCR, UNICEF, UNIFEM, WHO, Department of Reproductive Health and Research (RHR), Geneva: World Health Organization.

5. Heger AH, Ticson L, Guerra L, Lister J, Zaragoza T, et al. (2002) Appearance of the genitalia in girls selected for nonabuse: review of hymenal morphology and nonspecific findings. J Pediatr Adolesc Gynecol 15: 27-35.

6. Usta IM, Awwad JT, Usta JA, Makarem MM, Karam KS (1993) Imperforate hymen: report of an unusual familial occurrence. Obstet Gynecol 4: 655-656.

7. Dane C, Dane B, Erginbas M, Cetin A (2007) Imperforated hymen- A Rare Cause of Abdominal Pain: Two Cases and Review of the Literature. J pediatr adolesc gynecol 20: 245-247.

8. Brown Y, Calder B, Rae D (1989) Female circumcision. Can Nurs 85: 19-22.

9. Nour NM (2006) Urinary calculus associated with female genital cutting. Obstet Gynecol 107: 521-523. 